\title{
Walkability Perception in Asian Cities: A Comparative Study in Bangkok and Nagoya
}

\author{
Varameth Vichiensan ${ }^{1,2, *(1)}$ and Kazuki Nakamura ${ }^{3}$ \\ 1 Department of Civil Engineering, Faculty of Engineering, Kasetsart University, Bangkok 10900, Thailand \\ 2 Center for Logistics Engineering Technology and Management, Faculty of Engineering, Kasetsart University, \\ Bangkok 10900, Thailand \\ 3 Department of Civil Engineering, Meijo University, Nagoya 468-8502, Japan; knaka@meijo-u.ac.jp \\ * Correspondence: fengvmv@ku.ac.th
}

Citation: Vichiensan, V.; Nakamura, K. Walkability Perception in Asian Cities: A Comparative Study in Bangkok and Nagoya. Sustainability 2021, 13, 6825. https://doi.org/ $10.3390 /$ su13126825

Academic Editor: Luca Bertolini

Received: 14 May 2021

Accepted: 12 June 2021

Published: 16 June 2021

Publisher's Note: MDPI stays neutral with regard to jurisdictional claims in published maps and institutional affiliations.

Copyright: (c) 2021 by the authors. Licensee MDPI, Basel, Switzerland. This article is an open access article distributed under the terms and conditions of the Creative Commons Attribution (CC BY) license (https:// creativecommons.org/licenses/by/ $4.0 /)$.

\begin{abstract}
Asian cities are unique, where people may need more than just walking; however, the walkability research in a local context has received less attention. This paper analyses the walking needs and the influential factors of walking behavior in Asian cities. A comparative analysis in Bangkok and Nagoya is presented, taking into account the characteristics of local street design and development. Street evaluation experiments of various streets are conducted through 360-degree videos. The factor analyses indicate that the walking needs in both cities can be considered in two levels, but the components of the needs are different. Being smooth and having no obstacles are common basic needs. Safety and security are regarded as basic needs in Nagoya, but as higher-level needs in Bangkok. Attractiveness of activity and walk pleasure are the common upper-level needs. Street elements such as width, green, traffic, parking, pollution exposure, and activity are found to be influential on the walking needs. The structural equation models indicate that higher-level needs have more of an influence than the lower-level needs for walking behavior in Bangkok and for shop walking in Nagoya, while the basic need has more influence on walking willingness for transit access. These findings call for practical attention for street design and development where local context and street functions must be carefully considered.
\end{abstract}

Keywords: street design; Asian cities; walkability; factor analysis; structural equation modeling

\section{Introduction}

Walking used to be one of the charms of Asian cities in the old days, where vibrance and liveliness were unique characteristics. Activities in public spaces, in connection with walking, such as a street food or vending, are well-known examples. However, during the period of rapid motorization, attention and priority were given to cars rather than to pedestrian traffic. A lot of public space was allocated for road development rather than walking facilities. Large roads only allocated a certain amount of side pavement, namely the residual parts of vehicular spaces, to pedestrians, without any proper design. Small streets are likely to ignore spatial design for pedestrians, causing numerous conflicts among various street users. Consequently, many Asian cities are becoming less walkable, resulting in more accidents with pedestrians, inconvenience, and exposure to pollution.

In general, walkability is known as a measure of how friendly an area is to pedestrians and to the activity of walking. A walkable neighborhood has been found to be associated with a number of benefits across social, economic, environmental, and health outcomes [1]. Walkability is preferable for a healthy neighborhood, where children and elder people can walk to the store or school without the danger of being hit by a car or motorcycle, while people can access transit stations with safety and comfort, thus encouraging transit usage and reduce the dependency of travel by car. In addition, walkability is found to strongly and positively impact health by increasing the time spent on physically active travel, decreasing the body mass index, deceasing driving, and producing less emissions [2]. 
Walkability also has a positive impact on property value, as real estate is also likely more valuable in a more livable and walkable neighborhood.

The indexes for walkability may be measured throughout the world. Many of the walkability indexes have the common features of the Ds, including development density, diversity, and design [3]. The existing literature considers walkability at different scales. In a city or urban scale, walkability is considered to have a strong tie with the urban environment and physical activity, particularly in relation to density and diversity [1]. The walkability index developed for Vancouver, Canada, is based on the following four indicators: housing density, commercial density, degree of mixed land use, and road connectivity. Similarly, in New Zealand, walkability is evaluated as how the built environment is friendly to the presence of people living, shopping, visiting, enjoying, or spending time in the area [4]. In Australia, walkability is evaluated as the extent to which the built environment is a friendly area for pedestrians, and measures the impact of the built environment on walkability based on three factors: mixed-use planning, density, and street connectivity [5-7]. It was found that a compact and connected urban environment with a mixture of densities and land uses creates a shorter distance between desired destinations, thus encouraging people to walk for transportation [5]. In Italy, the walking suitability index of the territory (T-WSI) of a district, considering the 5D's of urban form, was developed based on 12 indicators that could be classified into four groups: practicability, safety, urbanity, and pleasantness [8-10]. A similar study in Malaysia found that the surrounding environment affected walkability, and it is influenced by the following three factors: density of settlements, street connections, and mixed land use [11]. There are also some differences in the effectiveness of the walkability indexes, depending on the local contexts. A review study found varying relationships between the built environment, play activity, and traffic safety associated with walkability for different age ranges [12]. A walkable neighborhood is preferable for children and the elderly, so that they can walk to the store or school without danger of an accident [13]. A multifactor walkability index for elderly health (WIEH), associating the adequacy level of public spaces to elderly walkability and physical exercise benefits was developed [14]. However, a study in Canada found that high walkability neighborhoods, based on eight evaluation items related to the urban environment, were less playable compared with low walkability neighborhoods [15]. A study in Seoul, Korea, found that housing prices were positively correlated with the walkability score in areas with low housing prices, however there was no significant association in areas with high housing prices [16].

Apart from the consideration of walkability with respect to the urban environment, many studies evaluated walkability based on the individual aspect of the street design. Various factors reportedly affect the walkability of a neighborhood, including, but not limited to, the quantity and quality of sidewalks, street trees, advertisement signboards, street merchants, motorcycles, and pedestrian crossings [17-22]. For instance, in California, the United States, walkability is considered based on individual street elements, and has been found to have a positive impact on transit-oriented developments [20]. The global walkability index (GWI) was proposed based on factors such as the safety and security of the walking environment, convenience and attractiveness, and support policies [18]. The GWI was also applied in Bandung, Indonesia [22]. Following GWI, a walkability audit tool was developed to assess pedestrian facilities, pedestrian conflicts, crosswalks, maintenance, path size, buffer, universal accessibility, aesthetics, and shade, which is advised for each road segment [21]. Based on GWI, the walkability of 13 Asian cities was evaluated by various items, including conflicts between pedestrians and other traffic, the availability of walking paths, availability of crossings, grade crossing safety, motorist behavior, amenities, disability infrastructure, obstructions, and security from crime, and the results revealed a low walkability in Asian cities [23].

These works underline the importance of walkability for neighborhood and street designs. Although walkability research has been extensively conducted in many parts of the world, it is still lacking in Asia. The Western experiences of walkability may be 
instructive, but walkability in an Asian context may be unique and different from typical American or European cities. However, it should address a range of street problems in Asian cities, such as narrow sidewalks, poor state of repair and maintenance, trees and street vendors blocking walkways, barriers of footbridges, motorcycles speeding on sidewalks, chaotic advertisement signboards, and highly commercialized building spaces. These problems themselves may also differ by development stage between growing cities and developed cities among Asian cities.

The objectives of this study are to identify the distinctive walking needs and their influence on walking behavior in Asian cities. Comparative experiments in Bangkok, Thailand, and Nagoya, Japan, are presented. The two cities are representative of Asian cities, but have different characteristics and are currently at different stages of urban space development for pedestrians.

The rest of the article is organized as follows. Section 2 summarizes the rationale of walking and describes the context of street design and development in Thailand and Japan. Section 3 outlines the methodology and describes the experiment cities, case study streets, evaluation indicators, street evaluation experiments, and the statistical analysis approaches. Section 4 presents the results of the comparative analyses for the two experiments. Section 5 discusses the findings. Finally, Section 6 concludes the paper.

\section{Walking Environment}

\subsection{Walking Need}

Walkability consists of street design, walking needs, and walking behavior [24]. The evaluation framework relates them to each other in such a way that the physical features of street design influence the willingness of walking behaviors through the perception of walking needs. From an ergonomics point of view, walking may be considered as an interaction between the complex system of urban space and people who live and walk in it, namely the human-environment interface (HEI) [25]. Quality HEI would meet people's requirements based on their well-being and safety needs, complemented by the usability needs attributed to accessibility [9]. Alternatively, in walkability studies, this can be translated to the perception elements of walking needs, which are classified into accessibility, safety, comfort, and pleasurability [26]. Pleasurability can come about in different ways, such as attractiveness or being interesting [27]. Walking needs can be interpreted as a hierarchy structure, from accessibility and safety as the lower-level needs, to comfort and pleasurability as higher-level needs [26]. Which level of need is concerned depends on its level of satisfaction, which may be affected by the street conditions for walking. A study in São Paulo, Brazil, found that safety and security were the most important factors, while attractiveness induced by land use diversity and commercial ground-floor façades positively influenced walkability [28]. Land use diversity can also be analyzed with functional mix measures such as an entropy index [29,30]. Based on the land use mix indicator, walking behavior, in the United States, has been found to be influenced by the neighborhood, house format, and car dependency level, in addition to the personal attitude of walking and satisfaction with the walking environment [31]. The walking needs hierarchy may be further modeled, based on the theory of Maslow's hierarchy of needs (1954), in a way that increases the demand for higher-level needs once lower-level needs are met [32].

\subsection{Street Design and Development in Asian Context}

The HEI is related to people's requirement for urban space to urban design elements through well-being (sunshine, ventilation, temperature, humidity, noise public lighting, glare, and level of services), safety (conflicts with motorized uses, slippery surface, and surface evenness), and usability (architectural barrier, bus stops, maintenance, cleanness, and adaptability) [8]. A walkability study in the US identified primary urban design objects, including those of land use (density, diversity and block size), transport (road lanes, crossing, and bus stop density), and street design (connectivity, building front, place to 
stay, and traffic buffer) [24]. Land use and transport factors are consistently considered in transit-oriented development (TOD) by urban designers and transport planners $[3,33]$. The importance of the street design objects is insisted upon by urban designers to promote public spaces on streets [34]. These include on-street social activities as dynamic objects of street design in order to attract pedestrians' interests, which are likely to take place on street edge spaces between walkways and buildings. The vision of future street improvements illustrates the street edge spaces between walkways and buildings for public spaces and between walkways and driveways for multi-modal spaces [35].

Street design in Asia is further characterized by informal activities, including street vendors and paratransit drivers. It can be seen as adaptive design, as street spaces are adaptively used by these local activities, particularly in street edge spaces [36]. Street vendors play important roles by providing essential daily activities for food, but they are concerning as they are obstacles for pedestrians. Thus, they have been banned by the government under urbanization pursuing public health improvements. Motorcycle taxis and other paratransit vehicles also provide convenient daily mobility in heavy traffic congestion, but they cause safety risks, not only for riders, but also for pedestrians [37]. Moreover, roadside street edges are often occupied by other objects of utility equipment, such as electric poles, street trees, and parking cycles, which can cause conflicts for pedestrians and transport activities. Furthermore, vehicles to do with MaaS (mobility as a service) are increasingly dominating on street, which may change the streetscape of mobility.

\subsubsection{Thai Streets}

Streets in developing countries, including Bangkok, Thailand, were mostly developed mainly for car traffic, while less attention was paid to pedestrian movement and convenience. More spaces were allocated as traffic lanes, while small spaces were provided as sidewalks for pedestrian. Regrettably, pedestrians in Bangkok mostly find the present walking environment unsafe and uncomfortable. A recent study in Bangkok pointed out that the walking environment has not been appropriately developed, particularly around urban railway stations; hence, it is neither safe nor comfortable for pedestrians to access the stations, and automobiles (buses, cars, are motorbikes) are heavily used for access [19]. An earlier study in Bangkok reported similarly that more than $25 \%$ of the sampled residents around urban railway stations judge the existing walking environment to be "not safe to walk", while more than $40 \%$ of motorcycle taxi users said they did not want to walk because they feared collision with vehicles on sidewalks [38]. Thus, there is a call for improvements in the walking environment to encourage walking. Another study found that the walking difficulty in the central area of Bangkok was due to the inadequacy of separation between pedestrians and vehicles, while many obstacles also existed on the sidewalk [39]. For transit walk, it was reported that not only the distance to the station, but also the walking amenities, physical characteristics, land-use patterns, street network structure, and connectivity to other modes of transportation were important factors affecting the propensity to walk to the stations [39]. The obstacles that cause walking inconvenience and safety include lack of equipment and facilities for pedestrians and disabled people, security, and continuation of sidewalk, pedestrian crossing, obstacles to walking, and driving on the sidewalk [40]. The attitude and acceptance of walking residents in the station TOD was found to be influenced by the perceived feelings and perceived benefits of walking. Walking acceptance or willingness is different for low-, medium-, and high-income walkers, which were analyzed with a structural equation model [41]. Moreover, Bangkok sidewalks often have motorcycle taxis running, crowds of street vendors selling food, and other retail. Although many of these amenities perhaps make Bangkok a more colorful and enjoyable place for tourists, these dangers and obstacles make Bangkok sidewalks less walkable and desirable for local people who live and work in the area. In contrast, some studies have debated that street vendors have been considered as a part of urban lives in Bangkok [42,43], as they have roles in the realms of poverty reduction, reducing disparity, and entrepreneurial development, and because of their ability to respond to the needs 
and lifestyles of younger generations, as well as to the needs of low- and medium-income groups because of the lower price of the goods and convenience of shopping. Furthermore, street food in Bangkok is well known among tourists and is portrayed as one of Bangkok's tourist attractions. However, some other issues arise, such as the inequality of using public spaces. The famous pedestrianized street Khao San road, one of the famous tourist spots in Bangkok is an example, where public spaces are traded, transferred, and deprived by only some businesses [44].

From a legal point of view, the city officials under the Bangkok Metropolitan Administration (BMA) have a practical duty to enforce the law under the Act on the Maintenance of Cleanliness and Orderliness in the Country, B.E. 2535 (1992). Keeping sidewalks safe for pedestrians is a difficult task because of the shortage of city officials, resulting in limited enforcement authority and power. For instance, the law punishes motorcyclists running on the sidewalk with a fine of up to 5000 baht, approximately US\$160. However, it is not easy for the city inspectors to catch them because they cannot issue a ticket to the violators on site like the traffic police can, but need to take them to the district office to pay the fine. Moreover, for economic and political reasons, in the past, the BMA temporarily allowed the sale of goods in public places or establishments, resulting in over 700 locations being permitted to more than 20,000 street vendors. As a result of the continuous strong demand and supply of street vending [42], the number of vendors has been increasing, thus causing obstacles not only to pedestrians on the sidewalk, but also to car traffic on road surfaces at many locations. Since 2014, these temporary vending places have been gradually disallowed under the operation known as "Returning the Pavements to the Public".

The BMA has been successful in improving the sidewalk, aiming to encourage more walking and expecting an increasing volume of pedestrians, so as to be in line with TOD concept. Physically, the sidewalks in most areas of Bangkok are now clear of vendors, and wide and clean pavements are apparent. The affected vendors were relocated to several designated selling areas. However, these vendor relocations were not appreciated by the vendors owing to the higher rent, but worse merchandise. There was also an argument that the BMA should not fully remove street vendors, but should realign the administration of street vending while reconsidering the roles and functions of their livelihood by having the vendors monitor and control overcrowding acting as street inspectors [45]. Presently, the BMA are implementing various measures to help affected vendors. These include negotiating with the designated market management for lower rent and organizing walking-street events; however, this has been hindered by the measures taken against the COVID-19 pandemic. On the other hand, some lanes of streets in the Yaowarat area, Bangkok's Chinatown, will be closed to provide more spaces for pedestrian and food vendors/buyers.

\subsubsection{Japanese Streets}

In Japan, street design is based on road structure, which is significantly attributed to post-war reconstruction from the 1950s [46]. According to this development, main urban streets were widened to accommodate the growing number of traffic vehicles and to secure emergency spaces for safety. In large cities, streets have been planned to be wider than $30 \mathrm{~m}$, which includes a wide space for walkways and driveways. In the city center of several cities, including Nagoya, 100-m-wide main streets have been introduced, with particularly wide walkways. However, when most streets were developed, priority was given to road traffic vehicles. Since the street structure ordinance was integrated into the road structure ordinance in 1958, all roads and streets have followed the single standard that determines road width based on traffic volume. As a result, street spaces for pedestrians have been mostly neglected, only possessing the minimum standards of the walkway width.

Moreover, road development was accompanied by increasingly strong regulations for road users, such as parking and vendors. In Japan, the Parking Lot Act was enforced in 1957, and on-street parking was regulated by the police. The regulation law for bicycle parking was introduced in 1980, which gave the authority of operation to local governments. In 
2006, the regulation became stronger by including motorcycles in the parking regulation and introducing private inspectors for the parking violations of all vehicles. Delivery vehicles and taxies are only allowed on-street parking in certain cases, only if the vehicles and spaces are given the permission, for which they temporarily occupy limited places. Recently, ride hailing systems have been integrated with existing taxi services. Sharing services for bicycles have been introduced, some of which use on-street parking spaces.

Vendors were popular as the part of traditional Asian culture, even in Japan, but they have been abandoned over the past decades. While they particularly increased in informal markets during the post-war period in the 1950s, regulations excluded them from road users toward the 1960s because of the problems of public health, traffic safety, and crimes. Nowadays, vendors only operate during holiday events and in tourist areas.

Until recently, there was not much street design for pedestrians in Japan. The equivalent approach took place as temporal events of street closure for shoppers, called "pedestrian paradise", started occurring from the 1970s in Tokyo. The original aim for it was to raise awareness of traffic safety in the face of motorization. Street closures became popular during festivals, which attracted vendors and street performers. However, it caused problems of noise, security, and surrounding traffic congestion, and the number of the events decreased during the 2000s. On the other hand, the current COVID-19 pandemic has stimulated a drastic policy shift to encourage more active engagement in street design. To support cafes and restaurants that are regulated for opening hours, the government loosened the regulation of street use and allowed for more flexibility with street use in order to eat and drink in 2020. Street use for activity spaces has been further legitimized to formally designate pedestrian streets in 2021. In this way, street improvements have been prepared for more multi-functional design in Japan.

\section{Methodology}

\subsection{Experiment Cities}

This study selected Bangkok and Nagoya as the experiment cities, where local inhabitants were sampled as subjects and were asked to evaluate the walkability of five case study streets. Bangkok and Nagoya have representativeness of Asian cities, but have different characteristics. The two cities are currently in different stages of development of urban spaces for pedestrians. Bangkok, the capital city of Thailand, is well-known for street liveliness because of its street vending, but this may have made the city less walkable. It is currently in the stage of improving the walking-related infrastructure in order to be safer and more convenient for pedestrians; however, this might make the cities less lively. On the other hand, Nagoya, the third largest city of Japan by population, has attained a very good infrastructure and environment for pedestrians, but may be considered less vibrant in terms of street activities. The city is now trying to welcome more street activities for both pedestrians and local inhabitants.

\subsection{Case Study Streets}

Five street sections in three international cities in the Asia-Pacific region were selected as case study streets for each of the experiment cities, namely: Bangkok and Nagoya. The case study streets were in Bangkok (Thailand), Nagoya (Japan), and Brisbane (Australia). Brisbane was added to the case study because the city center has been more active at introducing a pedestrian zone with activity spaces in the Western way. The three cities are all car-dependent, but their street designs vary. The case study streets are in the city centers and are located around rail transit stations. Among each of the five case study streets, two streets were familiar to the subjects, while the remaining three streets were unfamiliar or not likely known to the subjects, as summarized in Table 1 . To capture the walking experience, around-view video was recorded using a $360^{\circ}$ camera (Ricoh Theta V) while the surveyor walked along the case study street. The videos were omni-directional, so the watcher could freely choose sights within landscape. The sights could be maneuvered by dragging the mouse when viewing on computer monitor, or by panning on a gyro-equipped device 
such as a mobile phone or tablet. A more immersed feeling of viewing a 3D video can be perceived by using a head-mounted display, simply known as a virtual reality headset. For the experiments in this study, a short representative video clip of approximately 1-min long was trimmed from the raw video and was used for the walking evaluation experiments.

Table 1. Case study streets for the Bangkok and Nagoya experiments.

\begin{tabular}{cll}
\hline & \multicolumn{1}{c}{ Bangkok Experiment } & \multicolumn{1}{c}{ Nagoya Experiment } \\
\hline \multirow{2}{*}{ Familiar } & (1) Siam square district, Bangkok & (1) Sakae Hisaya-odori (south), Nagoya \\
& (2) Silom street, Bangkok & (2) Sakae Hisaya-odori (north), Nagoya \\
\hline \multirow{3}{*}{ Unfamiliar } & (3) Chula Soi 5, Bangkok & (3) Asoke Station Skywalk, Bangkok \\
& (4) Sakae Otsu-dori, Nagoya & (4) Soi Sukhumvit 23, Bangkok \\
& (5) Queen street mall, Brisbane & (5) Queen street mall, Brisbane \\
\hline
\end{tabular}

\subsubsection{For the Bangkok Experiment}

The five case study streets for the Bangkok experiment consisted of three streets in Bangkok, one in Nagoya, and one in Brisbane, and a snapshot of each is shown in Figure 1 panels (a) to (e), respectively.

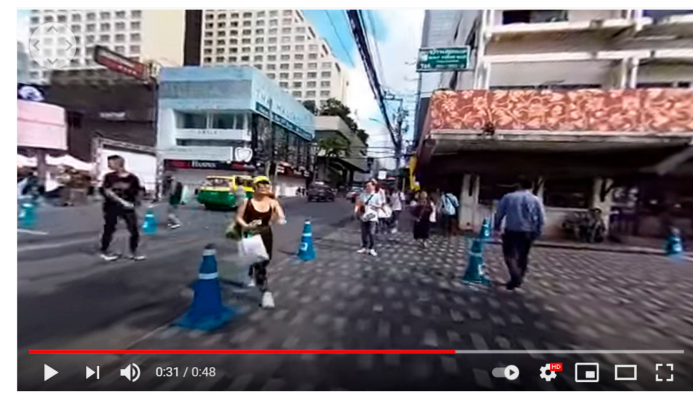

(a)

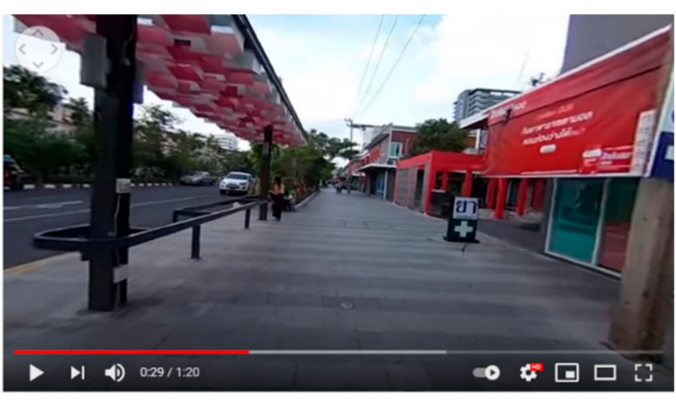

(c)

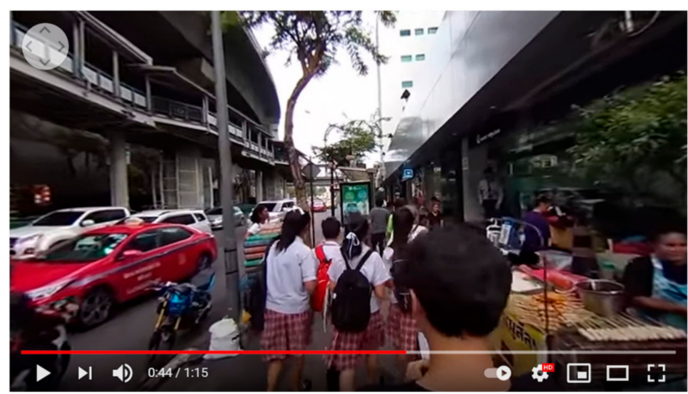

(b)

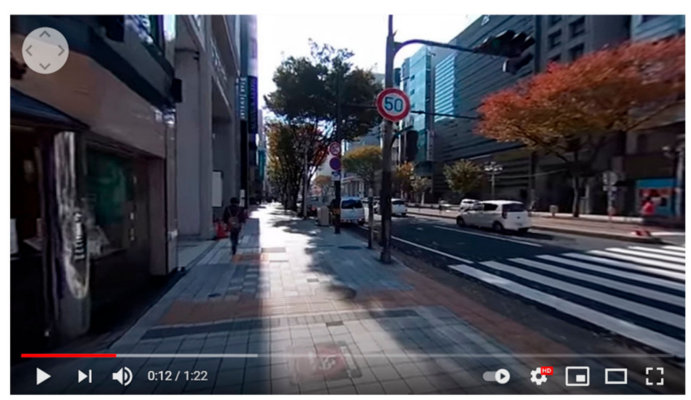

(d)

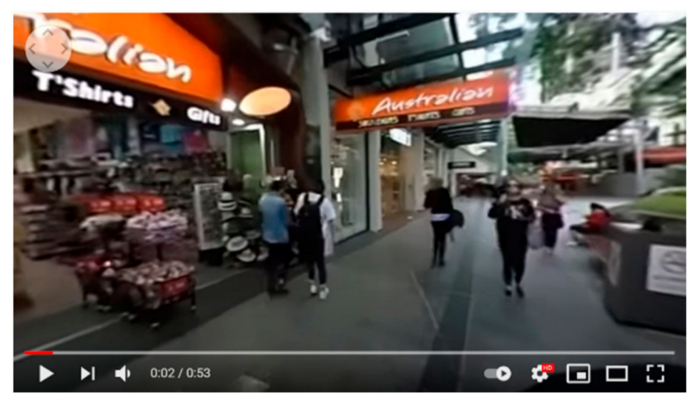

(e)

Figure 1. Five case study streets for the Bangkok experiment: (a) Siam Square district, Bangkok. (b) Silom street, Bangkok. (c) Chula Soi 5, Bangkok. (d) Sakae Otsu-dori, Nagoya. (e) Queen street mall, Brisbane. 
The first case study street is around Siam Square shopping district (panel a), around Siam Station, where two urban railway lines intersect, namely the BTS Sukhumvit and BTS Silom lines. The second case study street, Silom street (panel b), links the office building district to the intersection point of two railway lines, namely Sala Daeng station of the elevated BTS green line and Silom station of the underground blue line. These two streets are the typical walking spaces in the city center of Bangkok, where large spaces are allocated to car traffic, but a narrow area is provided for pedestrian traffic where vendors and other informal activities are obstacles to walking conveniently.

The third case study street is in Bangkok city center along the Green Avenue, the former name was Chula Soi 5 (panel c). The design of this street is not common in Bangkok, where a pedestrian sidewalk is provided with more space amid the greenery setting and it is well equipped with street elements. The street was recently redeveloped to be a pedestrian- and bicycle-friendly road, extending beyond the newly constructed green park which is the first green infrastructure hosted the state-of-the-art underground retention pond drainage facility for the city of Bangkok.

The fourth case study street is in Nagoya, Japan, namely Otsu-Dori street (panel d). It is known as a shopping high-street around the Sakae railway station, along which the streetside department stores are aligned. The street was traditionally kept as the North-South urban axis of Nagoya city for hundreds of years, and is still now the main arterial road for vehicle traffic, as well as the main shopping street for pedestrians walking on the wide sidewalks. Many urban centers are connected by the street, one of which is the Osu area with highly cultural places featuring a mixture of traditional culture and young culture in order to attract many visitors, including foreigners. The street is sometimes closed to traffic on the weekend for various pedestrian events, so-called "pedestrian paradise". The fifth case study street is Queen Street Mall near the central bus station in Brisbane, Australia (panel e). It was closed to traffic in 1981 and was expanded for the mega events, such as the Commonwealth Games and the Expo, and is now a Western commercial pedestrian zone in the city center near the Central rail station and the central bus terminal. The last two case study streets in Nagoya and Brisbane were also considered unfamiliar to the subjects in the Bangkok experiment.

\subsubsection{For the Nagoya Experiment}

The five case study streets in the Nagoya experiment include two familiar streets in Nagoya, two unfamiliar streets in Bangkok, and one unfamiliar street in Brisbane, shown in Figure 2. The first two case study streets of the Nagoya experiment are HisayaOdori avenue, under redevelopment next to Otsu Street in the Sakae district in Nagoya. Hisaya-odori avenue is a more familiar high-street for local people to walk, thanks to the surrounding flagship developments, such as department stores, TV tower, and central park. The avenues were built as a $100 \mathrm{~m}$-wide road in the post-war reconstruction plan more than 50 years ago. The middle part of the avenue was designed as the central park, and is being redeveloped to introduce more shops into the park. The side-streets are existing shopping streets with some traffic, which are the case study streets. One of the case studies, the South part (panel a) of the avenue, is aligned with street-side department stores. The North part (panel b) has more individual shops and offices with less pedestrians than the South part. The third case study street is located at one of the transport hubs in Bangkok's city center around Asoke station, where the elevated BTS Sukhumvit line and subway Blue line intersect. This area is a transportation hub in Bangkok, with many foreign people and facilities. The station is connected to shopping centers with a roofed and elevated pedestrian walkway, the so-called skywalk (panel c). The fourth case study street is in the same area, but on a back street (panel d), Soi, linking to an arterial road, namely Sukhumvit road. The fifth case study street is Brisbane's Queen Street mall, which is the same as that of the Bangkok experiment, and was described earlier (panel e). 


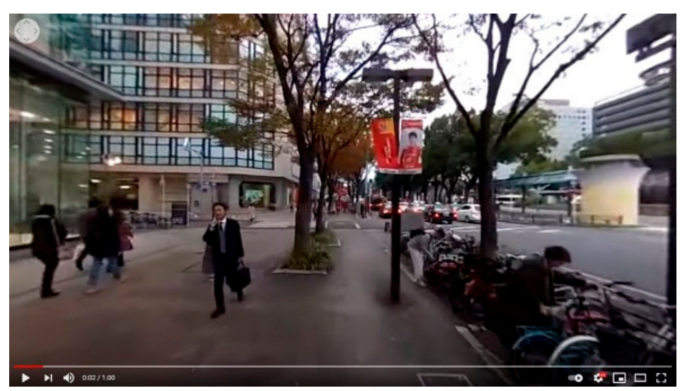

(a)

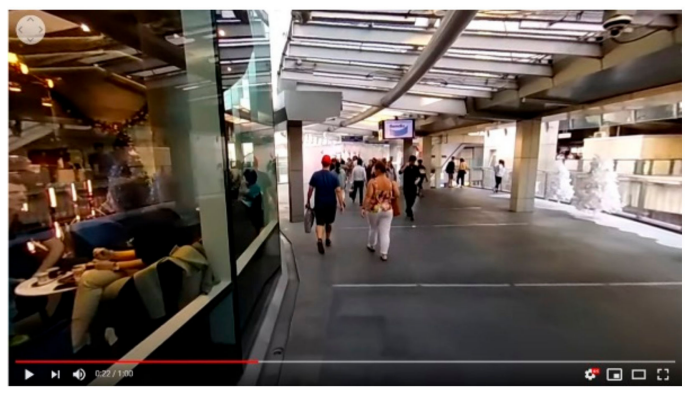

(c)

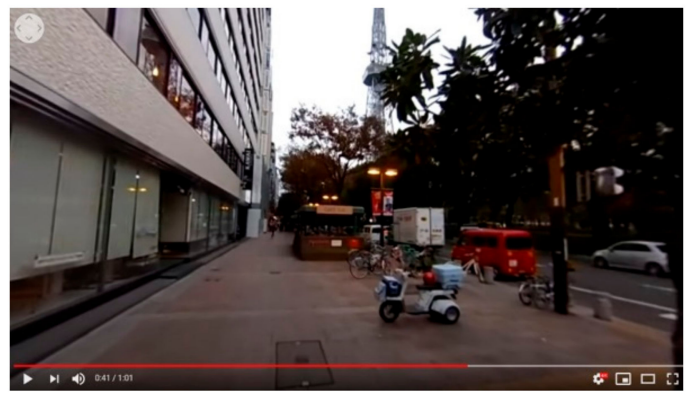

(b)

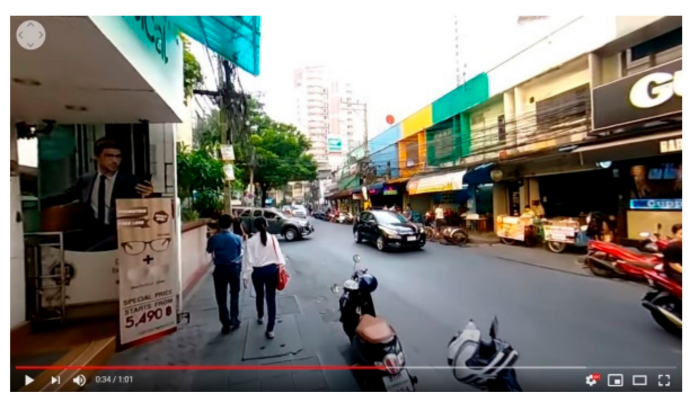

(d)

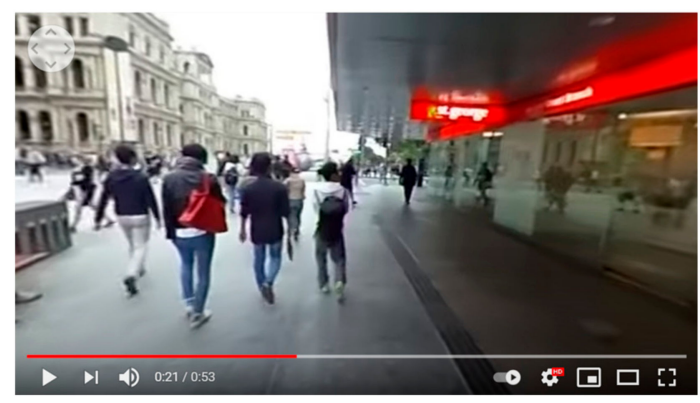

(e)

Figure 2. Five case study streets for the Nagoya experiment: (a) Hisaya-odori (South), Nagoya. (b) Sakae Hisaya-odori (North), Nagoya. (c) Asoke Station Skywalk, Bangkok. (d) Soi Sukhumvit 23, Bangkok. (e) Queen street mall, Brisbane.

\subsection{Evaluation Indicators}

The walkability evaluation was based on the indicators related to street design; walking needs, including lower-level and upper-level needs; and walking willingness. The indicators were selected with reference to previous studies [47,48], where the walking needs included convenience, safety, comfort, and attractiveness. Table 2 summarizes the indicators used in this study. They were developed in such a way that the evaluation could be scored in the same direction, i.e., a small value indicates less preferable, while a large value indicates more preferable. Among all of the indicators, many are common for the two experiment cities, such as width, activity, no obstacle, security, safety, and protection (shading or cover). Although the rest of the indicators are not literally the same for the two experiments, they are comparable. This fine selection was made to capture the local context and to extract the exact perception of the local subjects in each experiment. For example, in terms of quality, the pavement type is representative of the Bangkok experiment, while street parking is representative for the Nagoya experiment. Considering the impact of car traffic on walking, in the Bangkok experiment, pollution is used to emphasize how much air and noise pollution is locally produced by the nearby car traffic, while in the Nagoya experiment, traffic volume is used to represent the original source of annoyance. Next, considering tidiness, cleanliness is the major concern in Bangkok, where most of the sidewalks are not very clean yet, while greenery by trees is desired in Nagoya, where most 
of the sidewalks are basically clean. In terms of pleasantness, the Bangkok experiment used walking pleasure as a common perception, while the Nagoya experiment specifically considered vibrancy and a feeling of originality of the place as perceived by the pedestrian. Finally, walking willingness as an outcome indicator(s) was also selected according to the interests of walking based on the local contexts. The Bangkok experiment evaluated by the preference of walking over driving, as the travel mode was a primary choice for Bangkok local people. On the other hand, the Nagoya experiment evaluated by the willingness to walk as transit and to walk for shopping, with walking choices being made more according to purpose for the local Nagoya people.

Table 2. Evaluation indicators in the Bangkok and Nagoya experiments.

\begin{tabular}{ccc}
\hline & Bangkok Experiment & Nagoya Experiment \\
\hline \multirow{3}{*}{ Street design } & Width & Width \\
& Pavement & Street parking \\
& Less pollution & Traffic volume \\
& Cleanliness & Green \\
& Nearby activity & Street activity \\
\hline \multirow{2}{*}{ Walking needs } & Smoothness & Legible \\
& No obstacle & No obstacle \\
& Traffic safety & Cross safety \\
& Security & Security \\
& Shading or cover & Protection \\
& Pleasure & Vibrant \\
& & Original \\
\hline \multirow{2}{*}{ Walking willingness } & Walk preference & Walk for transit \\
& & Walk for shop \\
\hline
\end{tabular}

\subsection{Street Evaluation}

This study intends to evaluate the street design in virtual walking environments, although the accuracy of reproducing the real environment is out of the focus of the experiment. For each experiment in Bangkok and Nagoya, street evaluations were carried out by asking the subjects to watch the $360^{\circ}$ video of the corresponding case study streets that were uploaded to YouTube. After viewing each video, the subjects completed a questionnaire evaluating walkability according to walking needs and walking willingness indicators. The subjective level of street design, the satisfaction level of walking needs, and the willingness level of walking behaviors were rated on a 7-point Likert scale (strongly agree $=7$, agree $=6$, somewhat agree $=5$, neutral $=4$, somewhat disagree $=3$, disagree $=2$, and strongly disagree $=1$ ). For the willingness of walking behavior, the Bangkok experiment asked the subjects how much they would prefer walking rather than travelling by car, while the Nagoya experiment asked how much they were willing to walk as part of transit travel and shopping activity, separately.

The Bangkok experiment was carried out in September and December 2020. It had a total of 168 participants that currently lived in and knew the local context of walking in Bangkok, among which 60 participants were undergraduate and graduate engineering students in Kasetsart University, joining the experiment during class hours, while the remaining 108 participants were invited to join from online. Out of the total sample data, some did not complete watching all five of the case study streets due to various technical problems, while some did not answer the evaluation of the streets in a consistent manner. After the data cleaning and screening, the complete and rational data of 75 subjects, making 375 evaluations, were selected and used in the subsequent analysis. The subjects had a gender mix of $51 \%$ female and $49 \%$ male. The multiple age groups consisted of $22 \%$ 20 years old or less, 55\% 21-30 years old, 13\% 31-40 years old, and 10\% 41 years old or older. In terms of the main mode for daily travel for work or study, more than half of the subjects used private modes ( $48 \%$ private car and $23 \%$ private motorcycle), showing 
reliance on driving or riding. Public transport groups exhibited a mix of $15 \%$ railway, $5 \%$ bus, $5 \%$ motorcycle taxi, and $2 \%$ car taxi. Very few subjects $(2 \%)$ walked or cycled, as a main mode, to go to work or school.

The Nagoya experiment was carried out in December 2020 by a professional survey company, which consists of more than 4 million active subjects, living in Japan, in order to answer the online questionnaires. The whole data consisted of 600 subjects and used the street videos of more than 12 cities from all over the world. To make it comparable to the Bangkok experiment, the subjects were extracted to evaluate the same case study cities: Bangkok, Nagoya, and Brisbane. As a result, the selected subjects consisted of 125 local inhabitants, making 269 evaluations of the five case study streets in the three cities. The subject profiles were evenly distributed by gender and age (56\% male and $44 \%$ female; $28 \%$ 20-30 years old, 37\% 40-50 years old, and 35\% 60-70 years old). As for the occupations, $70 \%$ were workers and $29 \%$ non-workers, including students. Full-time workers were $58 \%$ and managerial workers are $2 \%$. In terms of daily travel modes, $66 \%$ of the subjects walked more than three times a week. After this, cars were the most popular travel mode for $40 \%$ of the subjects, followed by trains $(26 \%)$ and bicycles $(25 \%)$.

\subsection{Analysis}

\subsubsection{Descriptive Analysis}

For each experiment of Bangkok and Nagoya, descriptive analysis was conducted to summarize the obtained data of the indicator evaluation. The mean value of each indicator was computed as a central tendency measurement to describe the average perception of walkability and the preference of walking. Standard deviation was computed as a variability measurement. As multivariate normal distribution is a primary assumption of the analysis conducted in the subsequent section, the normality of the data was checked by the skewness and kurtosis statistics. Skewness measures the symmetry of the distribution, while kurtosis measures the peakedness or flatness of a distribution when compared with a normal distribution. For instance, a positively skewed distribution has relatively few large values and tails off to the right, while positive kurtosis indicates a relatively peaked distribution, and vice versa. The normality test statistics are based on the skewness and kurtosis values, as follows:

$$
\begin{aligned}
& z_{\text {skewness }}=\frac{\text { skewness }}{\sqrt{\frac{6}{N}}} \\
& z_{\text {kurtosis }}=\frac{\text { kurtosis }}{\sqrt{\frac{24}{N}}}
\end{aligned}
$$

where $N$ is the sample size. If either calculated $z$ value exceeds the specified critical value, then the distribution is non-normal in terms of that characteristic. The critical value is from a $\mathrm{z}$ distribution, based on the desired significance level. The most commonly acceptable critical values are \pm 2.58 for a 0.01 significance level and \pm 1.96 for a 0.05 significance level [49].

\subsubsection{Factor Analysis and Structural Equation Model}

For each experiment of Bangkok and Nagoya, exploratory factor analysis (EFA), confirmatory factor analysis (CFA), and structural equation modeling (SEM) were conducted. In the literature, EFA, CFA, and SEM were extensively employed and served as efficient tools to examine the relationship among the influential factors on the walking behavior. In the United States, SEM was developed to examine the factors influencing the walking behavior, where it was found that the walk preferences were affected by convenience of walking to a utilitarian destination such as shops and restaurants, as well as by safety and an enjoyable neighborhood environment [31]. In Delhi, India, CFA was employed to identify 20 built environment factors affecting walkability [17]. In Southeast Asian cities of Jakarta, Indonesia, and Kuala Lumpur, Malaysia, SEM was used to comparatively 
examine the factors influencing safety perception, and it was found that wariness toward motorcycles and the absence of other people discouraged walking [37]. In Bangkok, EFA, CFA, and SEM were employed to examine the influence of attitudes towards walking on acceptance to walk to a station within the TOD catchment area [41]. Recently, SEM was employed to evaluate the walkability in Bangkok and other cities in Japan and Australia with respect to street design indicators, and examined its influence on whether to walk for shoping [48].

In this study, an exploratory factor analysis (EFA) using principal component extraction and factor rotation was conducted to examine the underlying structure of the walking needs by using IBM SPSS Statistics 27 software. To test the suitability of the data for the factor analysis, the Kaiser-Meyer-Olkin (KMO) was determined (its value should be greater than 0.8) and Bartlett's test of sphericity was conducted (the $p$-value of the chi-square statistics in the hypothesis test must be less than 0.05) [49]. Factor loadings of 0.50 or greater were practically significant, and cross-loading items were eliminated [49]. Communality, which is the proportion of variable's variance explained by its loadings on the factors, was calculated as the sum of the squared loadings across the factors. It identifies the strength of the factors in explaining each variable, for which a high variable communality $(>0.50)$ indicates the set of factors that can explain much of the variance of the variable and can justify keeping the variable [49]. The reliability of the model was evaluated by the following three indices: Cronbach's alpha (its value should be greater than 0.7 ), construct reliability (its value should be greater than 0.7 ), and average variance extracted (its value should be greater than 0.5) [49]. The latent constructs identified through the EFA were used for the confirmatory factor analysis (CFA) to validate the measurement models using IBM SPSS AMOS 27 software. The goodness-of-fit of the estimated model was evaluated.

The satisfied measurement models were used in the following structural equation model (SEM), which examined the relationship between street design, walking needs, and walking willingness, consistent with the hierarchical structure of walking needs [26]. The SEM for the Bangkok and Nagoya experiments were developed using each case study street evaluation data. IBM SPSS AMOS 27 software was used. The overall model fit was evaluated by several recommended goodness-of-fit statistics and indices [49]. As absolute fit indices, the Chi-square $\left(\chi^{2}\right)$ statistics were determined to evaluate the fit between the observed and estimated covariance matrices, i.e., the data vs. the model. As the Chisquared test is sensitive and biased to sample size, the value is larger with a larger sample size. The normed Chi-square was then determined as a simple ratio of $\chi^{2}$ to the degrees of freedom for a model (CMIN/df); its value should be less than 5.0. The goodness-of-fit index (GFI), which evaluates the proportion of variance in the sample variance-covariance matrix, should be greater than 0.9. As an incremental fit index, the comparative fit index (CFI) was determined; its value should be equal to or greater than 0.9. As a badness-of-fit index, the root mean square error of approximation (RMSEA) was determined, and a value less than 0.08 indicates a good fit.

\section{Comparative Analysis Results}

\subsection{Bangkok Experiment}

\subsubsection{Descriptive Statistics}

The descriptive statistics of the case study street evaluation are shown in Table 3. The mean values range from 4.61 to 5.67. The upper-need indicators such as pollution, shade/cover, and security, were relatively lower than the lower-need indicators. The standard deviation values varied from 1.388 to 2.010. Satisfaction on the presence of obstacles, walkway width, and pollution varied considerably. The skewness statistics, ranging from -1.002 to -0.340 , and the kurtosis statistics, ranging from -1.002 to +0.481 , were within the acceptable range of \pm 2.58 at a 0.01 significance level. This indicates that the data satisfy the normality assumption. 
Table 3. Descriptive statistics of the Bangkok experiment.

\begin{tabular}{|c|c|c|c|c|c|}
\hline Variables & Descriptions & Mean & SD & Skewness & Kurtosis \\
\hline Width & I am satisfied with width of the walkway. & 5.31 & 1.912 & -0.914 & -0.446 \\
\hline Smooth & $\begin{array}{l}\text { I am satisfied with smoothness of the } \\
\text { walkway. }\end{array}$ & 5.41 & 1.679 & -0.998 & -0.053 \\
\hline Clean & $\begin{array}{l}\text { I am satisfied with cleanliness of the } \\
\text { walkway. }\end{array}$ & 5.39 & 1.728 & -0.997 & -0.078 \\
\hline Pavement & $\begin{array}{l}\text { I am satisfied with pavement material of } \\
\text { the walkway. }\end{array}$ & 5.67 & 1.388 & -1.050 & 0.481 \\
\hline Obstacle & $\begin{array}{l}\text { I am satisfied that the walkway has no } \\
\text { obstacle. }\end{array}$ & 4.82 & 2.010 & -0.567 & -1.002 \\
\hline Shading/cover & $\begin{array}{l}\text { I am satisfied with shade or covering for } \\
\text { the walkway. }\end{array}$ & 4.72 & 1.690 & -0.340 & -0.706 \\
\hline Less pollution & $\begin{array}{l}\text { I am satisfied that the walkway has low } \\
\text { pollution. }\end{array}$ & 4.61 & 1.830 & -0.390 & -0.886 \\
\hline Traffic safety & I feel safe with respect to nearby traffic. & 4.99 & 1.765 & -0.686 & -0.459 \\
\hline Security & I feel secure with respect to crime. & 4.77 & 1.574 & -0.414 & -0.437 \\
\hline Nearby activity & I am satisfied with the nearby activities. & 5.06 & 1.552 & -0.586 & -0.312 \\
\hline Pleasure & $\begin{array}{l}\text { I will feel pleasure if I walk on this } \\
\text { walkway. }\end{array}$ & 5.11 & 1.794 & -0.863 & -0.266 \\
\hline Prefer to walk & $\begin{array}{l}\text { I will prefer to walk than travel by car if I } \\
\text { walk on this walkway. }\end{array}$ & 5.00 & 1.878 & -0.793 & -0.482 \\
\hline
\end{tabular}

\subsubsection{Evaluation of the Case Study Streets}

The evaluation results of the five case study streets in the Bangkok experiment are compared in Figure 3. Apparently, Silom street is the worst in every aspect, while the Nagoya and Brisbane case study streets are superior. On the other hand, Chula Soi 5, which is a recently redeveloped street, is appreciated for its physical features, while the Siam Square shopping district is appreciated for its surrounding activity. In terms of street design, the Nagoya and Brisbane case study streets are wider, cleaner, and have a better pavement quality, while the absence of obstacles and shade/cover provided by trees or roofs are highly valued. The pedestrianized street of Brisbane is highly appreciated thanks to the surrounding shops and open-space activity, while the Greenery street of Nagoya is appreciated for its walking pleasure. For walking needs, the Brisbane and Nagoya case study streets are evaluated higher than the remaining three streets in Bangkok with respect to the upper-needs of safety, security, and less-pollution. However, among the three local streets, Chula Soi 5 outperforms the other two streets. As a result, walking willingness was found to be higher for the Nagoya, Brisbane, and Chula Soi 5 streets, compared with the two local streets in Bangkok. 


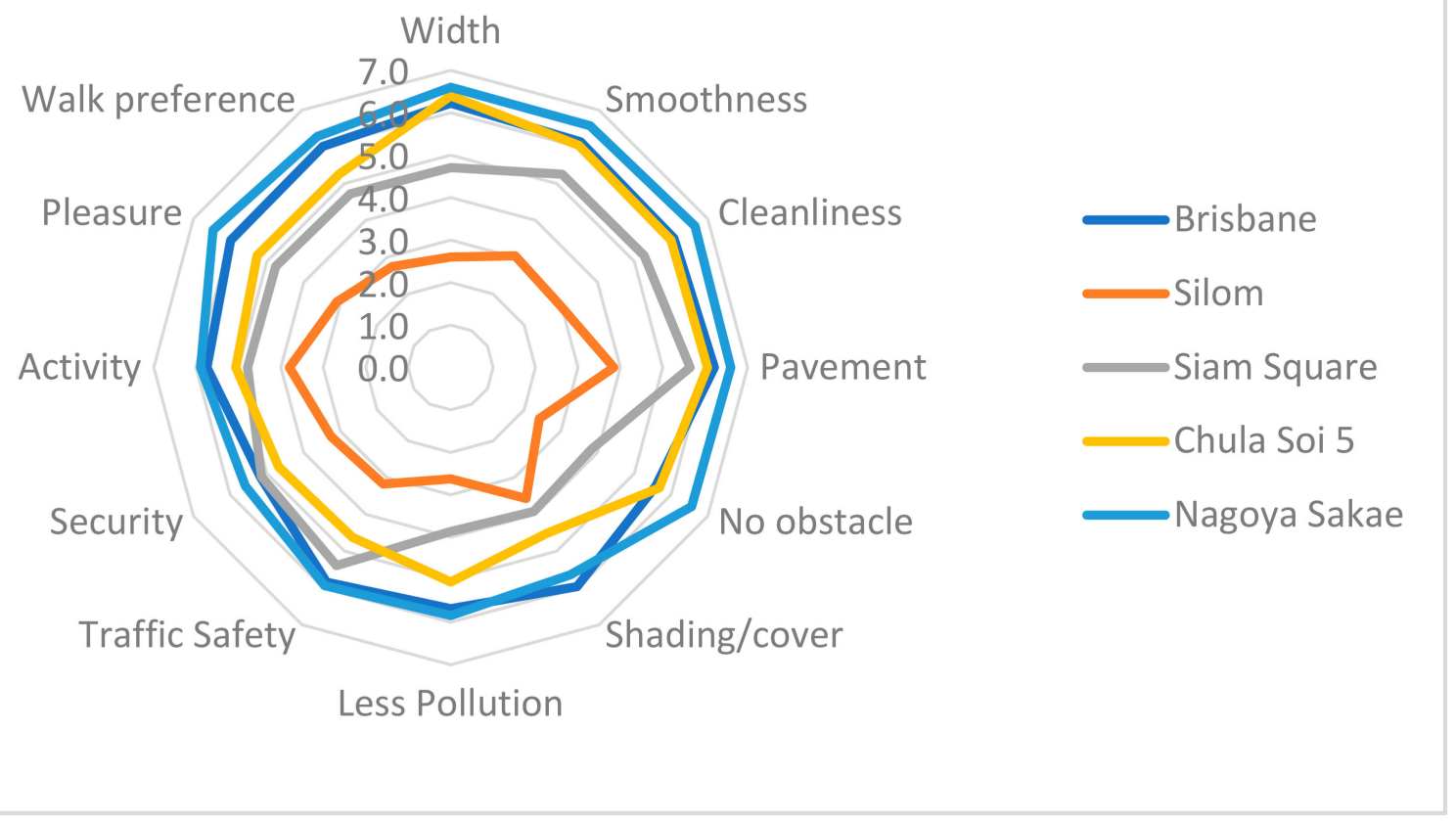

Figure 3. Evaluation of indicators, Bangkok experiment.

\subsubsection{Exploratory Factor Analysis}

From the Bangkok experiment data, the EFA on the seven measurement items extracted two factors with an eigenvalue greater than one, accounting for $80.576 \%$ of the total variance. After the Varimax rotation, the solution reflected the two-level walking needs, namely: lower- and higher-level needs. The rotated factor loadings of the two factors extracted by principal component analysis are shown in Table 4. As for KMO and Barlett testing, the $\mathrm{KMO}$ value is $0.951(>0.8)$ and the Chi-square value in Barlett's test of sphericity $\chi^{2}(\mathrm{df}=21)$ is 2172.59 with significance at $p=0.000$, indicating that the data can be used in the factor analysis.

Table 4. The Varimax rotated factor loadings for the Bangkok experiment. Bold: factor loading $>0.5$.

\begin{tabular}{|c|c|c|c|}
\hline & \multicolumn{2}{|c|}{ Components } & \multirow{2}{*}{ Communalities } \\
\hline & 1 & 2 & \\
\hline Smooth & 0.880 & 0.333 & 0.885 \\
\hline Clean & 0.871 & 0.362 & 0.890 \\
\hline No obstacle & 0.838 & 0.387 & 0.853 \\
\hline Shading/cover & 0.409 & 0.651 & 0.592 \\
\hline Traffic safety & 0.316 & 0.861 & 0.841 \\
\hline Security & 0.335 & 0.820 & 0.785 \\
\hline Pleasure & 0.690 & 0.565 & 0.795 \\
\hline
\end{tabular}

All seven variables making up each of these two factors are significant, all with a value well above the 0.50 cut-off. Both factors have three or more items per factor, with factor loadings ranging from 0.651 to 0.880 and communalities ranging from 0.592 to 0.890 . Most of the variables have high/significant loading on one factor only, except pleasure has cross-loadings. The first factor includes smooth, clean, and no obstacle variables, which reflect the lower-level walking needs, thus termed as convenience. The second factor includes traffic safety, security, shading/cover, and pleasure variables, which may reflect the higher-level walking needs, thus termed as comfort and pleasurability. Note that pleasure is kept in the second factor for interpretability although it is not well represented 
in the factor solution [49]. The reliability test result (Table 5) indicates that the constructs are strongly reliable: Cronbach's alpha $>0.7$, construct reliability $>0.7$, and average variance extracted $>0.5[49]$.

Table 5. Reliability test of construct of the Bangkok experiment.

\begin{tabular}{cccc}
\hline & Cronbach's Alpha & Construct Reliability & $\begin{array}{c}\text { Average Variance } \\
\text { Extracted }\end{array}$ \\
\hline Lower-level need & 0.931 & 0.898 & 0.745 \\
Higher-level need & 0.871 & 0.820 & 0.539 \\
\hline
\end{tabular}

\subsubsection{Structural Equation Model}

In the SEM of the Bangkok experiment, the structural model has the two endogenous latent variables based on the EFA results, namely: convenience of walking (lower-level need) and comfort and pleasurability (higher-level need). These latent constructs are affected by street design indicators. Pavement width and quality affect the convenience of walking, while activity attractiveness and low pollution affect comfort and pleasurability. The two latent constructs affect walking behavior, i.e., convenience and comfort, and pleasurability affect walking preference (against driving). The developed SEM with standardized path coefficients is shown in Figure 4.

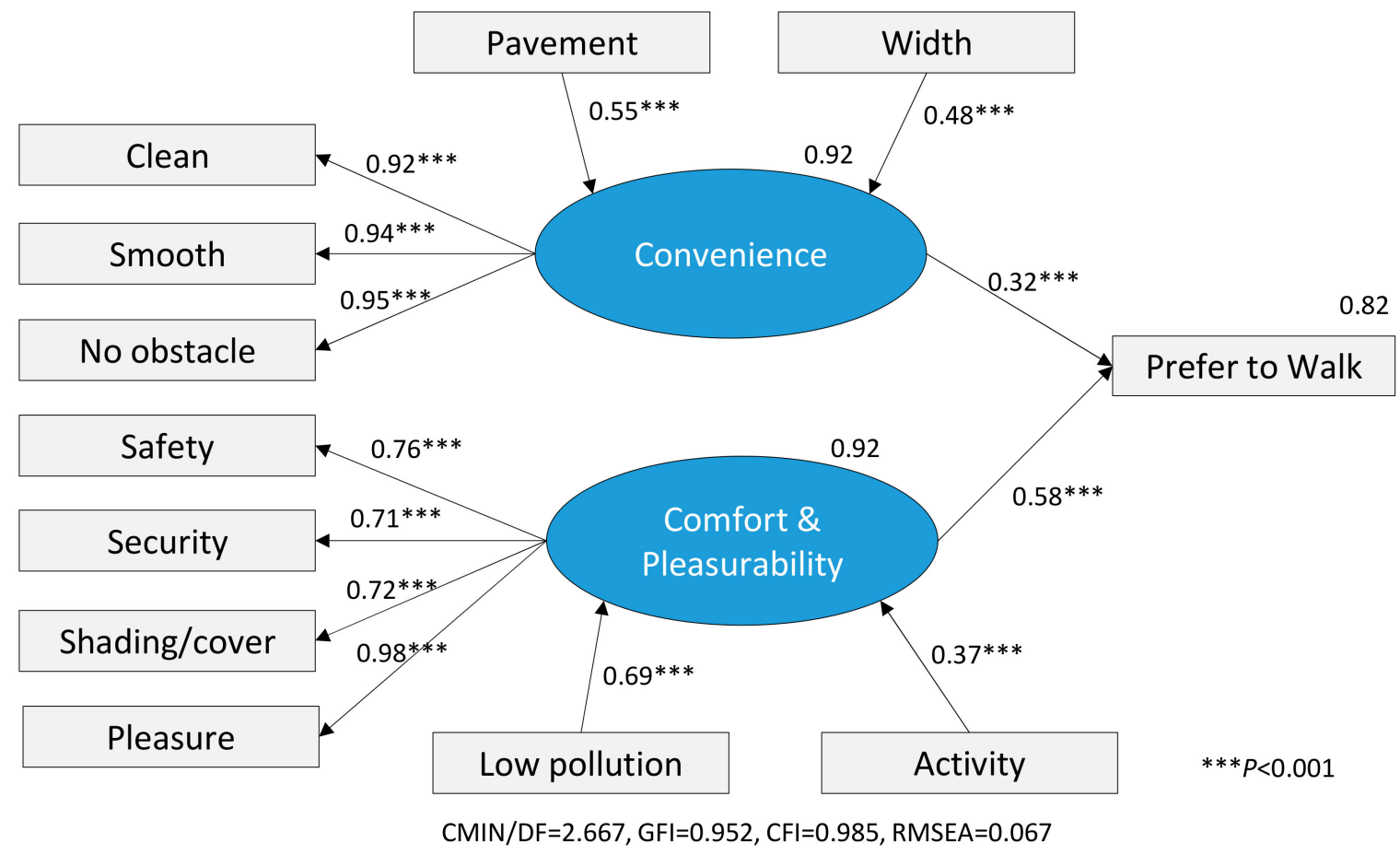

Figure 4. SEM model of the Bangkok analysis for preference to walk instead of drive.

The model is acceptable, as the goodness-of-fit indices satisfy the recommended values, as follows: $\mathrm{CMIN} / \mathrm{df}=2.667(<5), \mathrm{GFI}=0.952(>0.9), \mathrm{CFI}=0.985(>0.9)$, and $\mathrm{RMSEA}=0.067$ $(<0.08)$ [49]. All of the regression weights are strongly statistically significant with $p<0.001$. The model accounts for $92 \%$ variance in the convenience of walking, $92 \%$ variance in comfort and pleasurability of walking, and $82 \%$ variance in the preference of walking. It was found that the upper-level needs (walking comfort and pleasurability) have a larger influence on walking preference (against drive) than the lower-level needs (walking convenience). 


\subsection{Nagoya Experiment \\ 4.2.1. Descriptive Statistics}

The descriptive statistics of the case study street evaluation of the Nagoya experiment (Table 6) shows that the mean ranges from 3.48 to 4.65 . It is interesting that the evaluation results are relatively lower than the Bangkok experiment. However, the standard deviation is generally smaller than for the Bangkok experiment. The normality test of the data is satisfied within the ranges from -0.58 to 0.19 in skewness statistics, and from -0.85 to 0.14 in kurtosis statistics.

Table 6. Descriptive statistics of the Nagoya experiment.

\begin{tabular}{|c|c|c|c|c|c|}
\hline Variable & Description & Mean & SD & Skewness & Kurtosis \\
\hline Width & The walkway is wide. & 4.53 & 1.75 & -0.48 & -0.76 \\
\hline Street parking & $\begin{array}{l}\text { Many bicycles or motorcycles are parked } \\
\text { on the walkway. }\end{array}$ & 4.08 & 1.70 & -0.07 & -0.77 \\
\hline Traffic & Traffic is heavy on the driveway. & 4.26 & 1.63 & -0.21 & -0.66 \\
\hline Green & The walkway is green. & 3.48 & 1.55 & 0.19 & -0.68 \\
\hline Street activity & $\begin{array}{l}\text { Many activities take place on the } \\
\text { walkway. }\end{array}$ & 3.55 & 1.40 & 0.07 & -0.29 \\
\hline Legible & The street is legible. & 4.65 & 1.43 & -0.44 & -0.35 \\
\hline No obstacle & The street has less obstacle. & 4.19 & 1.64 & -0.25 & -0.85 \\
\hline Traffic safety & $\begin{array}{l}\text { The street is safe for crossing the } \\
\text { driveway. }\end{array}$ & 4.09 & 1.57 & -0.13 & -0.72 \\
\hline Security & The street is secure with respect to crime. & 4.21 & 1.30 & -0.31 & -0.03 \\
\hline Protection & The street is protected from weather. & 3.81 & 1.54 & -0.06 & -0.55 \\
\hline Vibrant & The street is vibrant. & 4.65 & 1.31 & -0.49 & 0.01 \\
\hline Original & The street is original. & 4.36 & 1.26 & -0.09 & 0.14 \\
\hline Transit walk & I am willing to walk for transit use. & 3.79 & 1.44 & 0.04 & -0.47 \\
\hline Shop walk & I am willing to walk for shopping. & 4.52 & 1.43 & -0.58 & 0.02 \\
\hline
\end{tabular}

\subsubsection{Evaluation of the Case Study Streets}

The evaluation results are compared among the case study streets (Figure 5). In terms of street design, the Nagoya streets have a wider walkway, more parking vehicles, more traffic volume, and more green streets. In comparison, in the Bangkok streets, for Sukhumvit Soi 23, the characteristics are a narrower walkway, more parking vehicles, heavier traffic, and more street activities, although the skywalk is protected from traffic. As the Brisbane case study street is pedestrianized, it has a wider walkway, less parking vehicles, less traffic volume, and more street activities. For the walking needs, the Nagoya case study streets are evaluated as being better for the lower-level needs, including for legiblity, no obstacles, safety, and security, but the higher-level needs, including protection, vibrancy, and originality, are evaluated worse. On the other hand, the Bangkok streets are evaluated in the opposite way, with a low-rated score in the lower-level needs and a high score in the upper-level needs, which is particularly the case for Chula Soi 5. The Brisbane case study street is evaluated highly for both needs. The scores of the Bangkok skywalk are relatively close to the Brisbane street, as they are both pedestrian-dedicated spaces.

Walking willingness is evaluated higher in Nagoya and Brisbane than for the Bangkok's streets. This may reflect the differences in the low-level needs. Nevertheless, the willingness for shop walk is evaluated higher for Bangkok and lower for the north street of Nagoya than the willingness for transit walk. This may be attributed to the differences in the higher-level needs. 


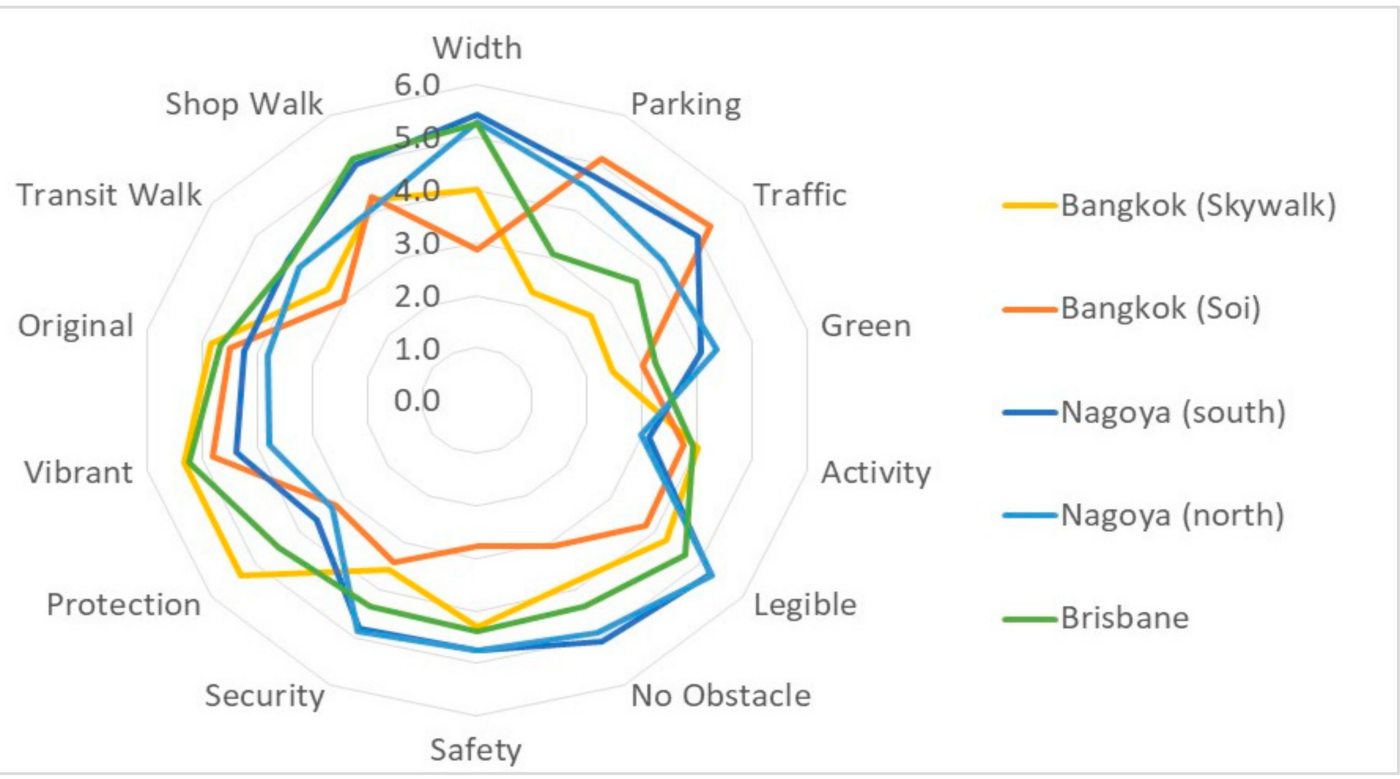

Figure 5. Evaluation of indicators from the Nagoya experiment.

\subsubsection{Exploratory Factor Analysis}

The EFA on the Nagoya experiment data classified the indicators of seven walking needs into two factors (Table 7). The KMO value was 0.77 , which is a sufficient data adequacy for the factor analysis. The Barlett's sphericity test is significant at $p=0.000$, indicating the suitability of the data. The factor loadings of all of the variables are greater than 0.5 . Each variable has a high/significant loading on one factor only, indicating good simple structure [49]. The communalities are also practically acceptable. The first factor includes legibility, no obstacles, safety, and security, which may reflect lower-level walking needs related to convenience and safety. On the other hand, the second factor accounts for higher-level walking needs related to comfort and pleasurability, including protection, vibrancy, and originality.

Table 7. The Promax rotated factor loadings for the Nagoya experiment. Bold: factor loading $>0.5$.

\begin{tabular}{|c|c|c|c|}
\hline & \multicolumn{2}{|c|}{ Component } & \multirow{2}{*}{ Communalities } \\
\hline & 1 & 2 & \\
\hline Legible & 0.78 & 0.00 & 0.61 \\
\hline No obstacle & 0.90 & -0.07 & 0.81 \\
\hline Safety & 0.84 & 0.07 & 0.71 \\
\hline Security & 0.72 & -0.02 & 0.52 \\
\hline Protection & 0.15 & 0.55 & 0.33 \\
\hline Vibrant & -0.14 & 0.87 & 0.78 \\
\hline Original & -0.04 & 0.68 & 0.46 \\
\hline
\end{tabular}

The reliability test (Table 8 ) shows better results in the lower-level needs, but both results are sufficient in terms of the Cronbach's alpha $(>0.7)$, composite reliability $(>0.5)$, and average variance extracted $(>0.5)$.

Table 8. The reliability test result of the Nagoya experiment.

\begin{tabular}{cccc}
\hline & Cronbach's Alpha & $\begin{array}{c}\text { Composite } \\
\text { Reliability }\end{array}$ & $\begin{array}{c}\text { Average Variance } \\
\text { Extracted }\end{array}$ \\
\hline Lower-Level Need & 0.88 & 0.89 & 0.68 \\
Higher-Level Need & 0.72 & 0.73 & 0.47 \\
\hline
\end{tabular}




\subsubsection{Structural Equation Model}

An SEM model was developed with the case study street evaluation data in the Nagoya experiment (Figure 6). The model structure was constructed in such a way that the street design indicators affected the walking needs and the walking needs consequently affected walk willingness. The indicators of walk willingness were tested for two types of behaviors: walk for transit use and walk for shopping. The estimated model is shown in Figure 6, where the standardized regression coefficients and the goodness-of-fit indices are noted.

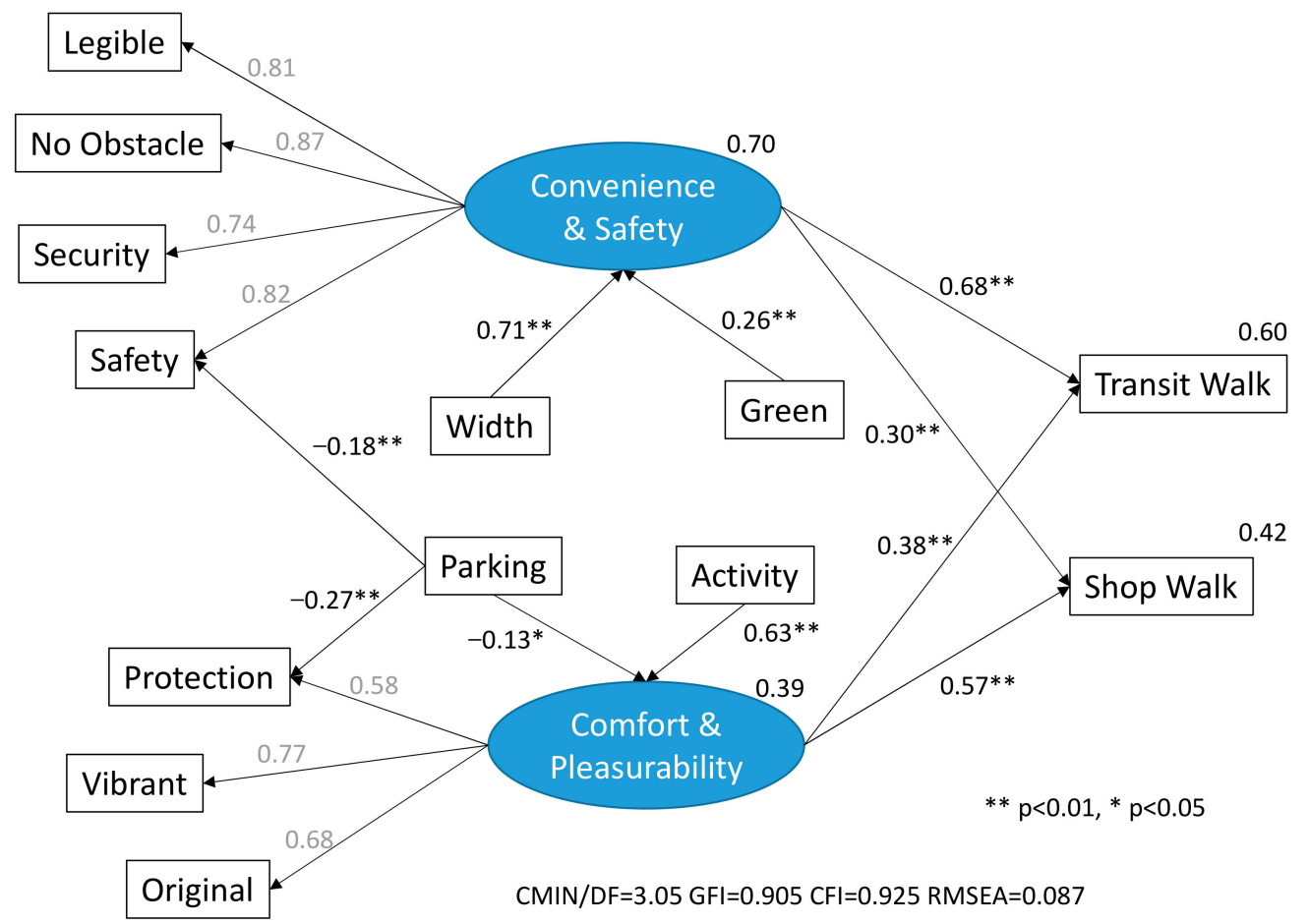

Figure 6. SEM model of the Nagoya analysis for transit and shop walks.

The model is judged satisfactory as all of the parameters are statistically significant, where most of the goodness-of-fit indictors are within the acceptable range for $\mathrm{CMIN} / \mathrm{df}=3.05(<5), \mathrm{GFI}=0.905(>0.9)$, and CFI $=0.925(>0.9)$, while RMSEA $=0.087$ is marginal $(<0.08$ good). The street design factors influence walking needs significantly as the model accounted for $70 \%$ of variance in convenience and safety, and $39 \%$ of comfort and pleasurability. Width, greenery, and street activity positively satisfied the walking needs, while street parking negatively impacted comfort and pleasure as well as safety. Likewise, the walking needs influenced walking behavior significantly, as the model accounted for $60 \%$ of variance in transit walk willingness and $42 \%$ shop walk willingness. It was found that the lower-level needs for convenience and safety affected transit walk willingness more significantly than comfort and pleasurability. On the other hand, the impact of the higher-level needs for comfort and pleasurability was more dominating for shop walk.

\section{Discussions}

\subsection{Street Design}

The comparative analysis in Bangkok and Nagoya revealed some common characteristics that could imply a representativeness of Asian streets. As walkable neighborhood is preferable for pedestrians of various ages walking for different trip purposes, the street design characteristics play important roles. The SEM results (Figures 4 and 6) show that street elements such as walkway width, walkway quality (pavement and the absence of street parking) and tidiness (cleanliness and greenery) have significant influences on satisfying 
one's walking needs, conforming to the state-of-practices around the world $[1,2,4,5,11]$. This study found that activities fulfill the walking needs in terms of comfort and pleasurability, complying with the literature finding them to be part of enjoyment [4] or urbanity [10], and having unique and wider roles $[40,46]$. In addition, this study included informal activity in the walkability evaluation, as it is one of the unique characteristics of Asian streets.

\subsection{Walking Preference}

The EFA results of both experiment cities are in line with the literature of the walking needs hierarchy [26], by having two factors of lower- and higher-level needs; however, their items and values are different. For the lower-level (or basic) needs, smoothness (legible) and no obstacles are common in both cities. Cleanliness is additionally included in Bangkok, while safety and security are additionally included in Nagoya. As safety and security are included in the higher-level need in Bangkok, more basic needs may be included in the lower-level needs in Bangkok than in Nagoya. This may indicate that safety and security in the street environment are not satisfactory in Bangkok. For the higher-level needs, shade (protection) and pleasure (vibrant) are common in both cities. As originality is included in the higher-level need in the Nagoya experiment, it may not be satisfied the originality of the street environment, despite the sufficiency of convenience and safety.

The SEM results show more details of the influential mechanisms from street design to walking behavior through walking needs. The lower-level needs are affected by street width in both cities. While street width is more significant in the Nagoya experiment, pavement quality is more significant in the Bangkok experiment. This may suggest that the pavement conditions are not satisfactory in Bangkok. In the Nagoya experiment, greenery additionally contributes to the lower-level needs. On the other hand, the higherlevel needs are affected by activity in both experiments. This is more significant in the Nagoya experiment, as activities such as vendors, may be perceived as obstacles in Bangkok. Despite this, it showed a positive impact of activity on walking perception even in Bangkok, which suggests the positive contribution of vendors. However, Bangkok has a more significant impact of traffic (low pollution) at higher-level needs. The higher-level need is more significantly influential on waking behaviors, namely: the walking preference over driving in the Bangkok experiment and walking willingness for shopping in the Nagoya experiment. Nevertheless, the impact of walking needs on behavior may depend on the purpose of walking. In Nagoya, the lower-level need is more significant for walking willingness for transit use. These results imply that in developing countries, where the infrastructure for walking is not properly provided nor maintained in a good manner, the physical design and condition of the walkway are regarded as lower-level (primary) needs, while safety and security are regarded as higher-level (secondary) needs. However, it is the higher-level needs, particularly safety and security, that have a larger influence on walking behavior. These findings are in line with previous research $[17,23,28]$.

This study empirically confirmed the validity not only of the classification of walking needs [26], but also of the hierarchy of the needs [32]. According to the results, the needs can be classified mainly according to convenience (usability) and comfort and pleasurability (well-being). On the other hand, the results that safety can be included in both factors suggests the interrelationship between need, in a consistent way with the hierarchy. The contribution of this study is the finding that how needs are interrelated depends on the built environment, attributed to the development stage. While the insufficiency of safety in street design may make the safety need associated with the convenience need, sufficiency may make it associated with the comfort need. Consequently, this advanced the theory of the needs-design relationship [25], as street design may affect multiple needs.

Moreover, this study provided empirical evidence for the impact of walking needs on walking behavior. The literature of empirical studies on the relationship between the built environment and walking behavior has paid more attention to the behaviors of travel and physical activities $[10,13,20,29,31,41]$. More attention needs to be paid to a range of activities, including street activities [34]. The contribution of this study can be found in the 
finding that needs affect walking behaviors depending on the local contexts, such as the development stage and walking purposes.

\subsection{Implication for Street Design}

As walking is a basic element for transit-oriented development (TOD), the responsible authorities need to carefully consider the pedestrian needs, and design and develop streets that match the local context. Walking in an Asian cities context originally involved adaptive street use for daily activities beyond the basic functions of a street, but street development is likely to exclude these activities, giving priority to road vehicle as a result of rapid motorization. The results indicate that street design needs to take into account walking needs, which depend on the spatial context of street functions. As implication for street design in Asian cities, a wide street with a good pavement is no longer sufficient, but street activities such as food and good merchants are also indispensable. Proper consideration and management of such activities may also be essential to keep the basic function of streets. Such street design can be achieved by the street management of local communities, as has been pointed out in the previous study [45].

Asian growing cities still have urban local communities, as in Soi, but they have been threatened to be weakened and segregated under the rapid urbanization and motorization. This may imply that the early implementation of street design may be more effective. A good balance for street design and social needs would further enhance urban sustainability in terms of improving economic efficiency, increasing equity, reducing the urban poor, increasing transit use and non-motorized transport, and reducing reliance on car usage, meaning less energy consumption and at the same time protecting the environment. Accordingly, more strategic approaches are needed in street design for all of Asia.

\section{Conclusions}

This study presented an analysis of the walking needs in an Asian context with a comparative study in Bangkok and Nagoya. It empirically showed that, while convenience is included in the fundamental needs of walking, comfort and pleasurability are higherlevel needs in both cities, and safety is a higher-level need in Bangkok. This may be attributed to the poorer street conditions in Bangkok, where narrow and low-quality pavements are still problematic, and the conflicts between pedestrians and vehicles are uneasy tasks because of extremely serious traffic congestion. Despite the controversy that vendors occupy street spaces in unorganized ways thus creating obstacles, their roles as activities are important for higher-level needs. As higher-level needs may be related with walking for activities, street improvements are required in order to enhance them so as to encourage walking in Bangkok. This is also indicative for Nagoya, where street activities have been lost through urbanization. This study successfully included informal activities in the walkability evaluation, which differentiate Asian streets from the Western world. The findings in this study shed some light on more practical street design, which matches the unique characteristics of growing Asian cities.

Author Contributions: Conceptualization, V.V. and K.N.; funding acquisition, K.N.; investigation, V.V. and K.N.; methodology, V.V. and K.N.; validation, V.V. and K.N.; writing, V.V. and K.N. All authors have read and agreed to the published version of the manuscript.

Funding: This research was funded by the Science and Technology Research Partnership for Sustainable Development (SATREPS) (JST/JICA JPMJSA1704).

Institutional Review Board Statement: Not applicable.

Informed Consent Statement: Not applicable.

Acknowledgments: The authors are thankful to Yoshitsugu Hayashi, Chubu University, and Kenji Doi, Osaka University, for their valuable comments for the study. Special appreciation is due to Wiroj Rujopakarn, Kasetsart University, for advice on EFA and SEM. 
Conflicts of Interest: The authors declare no conflict of interest. The funders had no role in the design of the study; in the collection, analyses, or interpretation of data; in the writing of the manuscript; or in the decision to publish the results.

\section{References}

1. Frank, L.D.; Devlin, A.; Johnstone, S.; Loon, J.V. Neighbourhood Design, Travel, and Health in Metro Vancouver: Using a Walkability Index; University of British Columbia: Vancouver, BC, Canada, 2010.

2. Frank, L.D.; Sallis, J.F.; Conway, T.L.; Chapman, J.E.; Saelens, B.E.; Bachman, W. Many Pathways from Land Use to Health: Associations between Neighborhood Walkability and Active Transportation, Body Mass Index, and Air Quality. J. Am. Plan. Assoc. 2006, 72, 75-87. [CrossRef]

3. Cervero, R.; Kockelman, K. Travel demand and the 3Ds: Density, diversity, and design. Transp. Res. Part D Transp. Environ. 1997, 2, 199-219. [CrossRef]

4. NZ Transport Agency. Guide to Undertaking Community Street Reviews; NZ Transport Agency: Wellington, New Zealand, 2010.

5. Gebel, K.; Bauman, A.; Owen, N.; Foster, S.; Giles-Corti, B. Position Statement: The Built Environment and Walking; National Heart Foundation: Melbourne, Australia, 2009.

6. National Heart Foundation. Neighbourhood Walkability Checklist-How Walkable Is Your Community? National Heart Foundation: Melbourne, Australia, 2011.

7. Habibian, M.; Hosseinzadeh, A. Walkability index across trip purposes. Sustain. Cities Soc. 2018, 42, 216-225. [CrossRef]

8. D'Alessandro, D.; Valeri, D.; Appolloni, L. Reliability of T-WSI to Evaluate Neighborhoods Walkability and Its Changes over Time. Int. J. Environ. Res. Public Health 2020, 17, 7709. [CrossRef] [PubMed]

9. Appolloni, L.; Giretti, A.; Corazza, M.; D'Alessandro, D. Walkable Urban Environments: An Ergonomic Approach of Evaluation. Sustainability 2020, 12, 8347. [CrossRef]

10. Appolloni, L.; Corazza, M.V.; D’Alessandro, D. The Pleasure of Walking: An Innovative Methodology to Assess Appropriate Walkable Performance in Urban Areas to Support Transport Planning. Sustainability 2019, 11, 3467. [CrossRef]

11. Azmi, D.I.; Ahmad, P. A GIS Approach: Determinant of Neighbourhood Environment Indices in Influencing Walkability between Two Precincts in Putrajaya. Procedia Soc. Behav. Sci. 2015, 170, 557-566. [CrossRef]

12. McGrath, L.J.; Hopkins, W.G.; Hinckson, E.A. Associations of Objectively Measured Built-Environment Attributes with Youth Moderate-Vigorous Physical Activity: A Systematic Review and Meta-Analysis. Sports Med. 2015, 45, 841-865. [CrossRef]

13. Stafford, L.; Baldwin, C. Planning Walkable Neighborhoods. J. Plan. Lit. 2017, 33, 17-30. [CrossRef]

14. Alves, F.; Cruz, S.; Ribeiro, A.; Silva, A.B.; Martins, J.; Cunha, I. Walkability Index for Elderly Health: A Proposal. Sustainability 2020, 12, 7360. [CrossRef]

15. Janssen, I.; King, N. Walkable school neighborhoods are not playable neighborhoods. Health Place 2015, 35, 66-69. [CrossRef]

16. Kim, E.J.; Kim, H. Neighborhood Walkability and Housing Prices: A Correlation Study. Sustainability 2020, 12, 593. [CrossRef]

17. Bivina, G.; Gupta, A.; Parida, M. Influence of microscale environmental factors on perceived walk accessibility to metro stations. Transp. Res. Part D Transp. Environ. 2019, 67, 142-155. [CrossRef]

18. Krambeck, H.V. The Global Walkability Index; Massachusetts Institute of Technology: Cambridge, MA, USA, 2006.

19. Ozawa, H.; Fukuda, A.; Malaitham, S.; Vichiensan, V.; Luathep, P.; Numa, H. Evaluation of walking environments around urban railway stations in Bangkok and consideration of improvement plans. Asian Transp. Stud. 2021, 7, 100038. [CrossRef]

20. Park, S.; Deakin, E.; Jang, K. Can Good Walkability Expand the Size of Transit-Oriented Developments? Transp. Res. Rec. J. Transp. Res. Board 2015, 2519, 157-164. [CrossRef]

21. Smith, L. Walkability Audit Tool. Work. Health Saf. 2015, 63, 420. [CrossRef] [PubMed]

22. Wibowo, S.S.; Tanan, N.; Tinumbia, N. Walkability Measures for City Area in Indonesia (Case Study of Bandung). J. East. Asia Soc. Transp. Stud. 2015, 11, 1507-1521. [CrossRef]

23. Leather, J.; Fabian, H.; Gota, S.; Mejia, A. Walkability and Pedestrian Facilities in Asian Cities State and Issues; Asian Development Bank: Mandaluyong, Philippines, 2011.

24. Ewing, R.; Bartholomew, K. Pedestrian E Transit-Oriented Design; Urban Land Institute: Washington, DC, USA, 2013.

25. Dul, J.; Bruder, R.; Buckle, P.; Carayon, P.; Falzon, P.; Marras, W.S.; Wilson, J.R.; Van Der Doelen, B. A strategy for human factors/ergonomics: Developing the discipline and profession. Ergonomics 2012, 55, 377-395. [CrossRef] [PubMed]

26. Alfonzo, M.A. To Walk or Not to Walk? The Hierarchy of Walking Needs. Environ. Behav. 2005, 37, 808-836. [CrossRef]

27. Speck, J. Walkable City: How Downtown Can Save America, One Step at a Time; North Point Press: New York, NY, USA, 2012.

28. Lamour, Q.; Morelli, A.M.; Marins, K.R.D.C. Improving walkability in a TOD context: Spatial strategies that enhance walking in the Belém neighbourhood, in São Paulo, Brazil. Case Stud. Transp. Policy 2019, 7, 280-292. [CrossRef]

29. Mavoa, S.; Eagleson, S.; Badland, H.M.; Gunn, L.; Boulange, C.; Stewart, J.; Giles-Corti, B. Identifying appropriate land-use mix measures for use in a national walkability index. J. Transp. Land Use 2018, 11, 11. [CrossRef]

30. Christian, E.H.; Bull, F.C.; Middleton, N.J.; Knuiman, M.W.; Divitini, M.L.; Hooper, P.; Amarasinghe, A.; Giles-Corti, B. How important is the land use mix measure in understanding walking behaviour? Results from the RESIDE study. Int. J. Behav. Nutr. Phys. Act. 2011, 8, 1-12. [CrossRef]

31. Coogan, M.A.; Adler, T.; Karash, K. The paths from walk preference to walk behavior: Applying latent factors in structural equation modeling. J. Transp. Land Use 2012, 5, 68-82. [CrossRef] 
32. Doi, K.; Kii, M.; Nakanishi, H. An Integrated Evaluation Method of Accessibility, Quality of Life, and Social Interaction. Environ. Plan. B Plan. Des. 2008, 35, 1098-1116. [CrossRef]

33. Calthorpe, P. The Next American Metropolis: Ecology, Community, and the American Dream; Princeton Architectural Press: New York, NY, USA, 1993.

34. Gehl, J. Life Between Buildings: Using Public Space; Island Press: Washington, DC, USA, 2003.

35. National Association of City Transportation Officials. Blueprint for Autonomous Urbanism, 2nd ed.; National Association of City Transportation Officials: New York, NY, USA, 2019.

36. Oranratmanee, R.; Sachakul, V. Streets as Public Spaces in Southeast Asia: Case Studies of Thai Pedestrian Streets. J. Urban Des. 2014, 19, 211-229. [CrossRef]

37. Hidayati, I.; Tan, W.; Yamu, C. How gender differences and perceptions of safety shape urban mobility in Southeast Asia. Transp. Res. Part F Traffic Psychol. Behav. 2020, 73, 155-173. [CrossRef]

38. Pongprasert, P.; Kubota, H. Switching from motorcycle taxi to walking: A case study of transit station access in Bangkok, Thailand. IATSS Res. 2017, 41, 182-190. [CrossRef]

39. Chalermpong, S.; Wibowo, S.S. Transit station access trips and factors affecting propensity to walk to transit stations in Bangkok, Thailand. J. East. Asia Soc. Transp. Stud. 2007, 7, 1806-1819. [CrossRef]

40. Boonon, N.; Limpaseni, W. Sidewalk Development for Convenient Bangkok Metropolitan: A Case Study of Sidewalk Along BTS Light Green Line. Vajira Med. J. 2020, 64, 213-222. [CrossRef]

41. Pongprasert, P.; Kubota, H. TOD residents' attitudes toward walking to transit station: A case study of transit-oriented developments (TODs) in Bangkok, Thailand. J. Mod. Transp. 2018, 27, 39-51. [CrossRef]

42. Nirathron, N.; Yasmeen, G. Street vending management in Bangkok: The need to adapt to a changing environment. J. Public Space 2019, 4, 15-32. [CrossRef]

43. Tangworamongkon, C. Street Vending in Bangkok: Legal and Policy Frameworks, Livelihood Challenges and Collective Responses; WIEGO Law and Informality Resources: Cambridge, MA, USA, 2014.

44. Musigakama, P. The Commodification of Public Spaces on Khao San Road. Nakhara: J. Environ. Des. Plan. 2019, 17, 81-96.

45. Nirathron, N. Fighting Poverty from the Street: A Survey of Street Food Vendors in Bangkok; International Labour Office: Bangkok, Thailand, 2006.

46. Niitani, Y. History of Sidewalks in Japan-A Study on Transition of Structural Standard. IATSS Rev. 1981, 7, 4-14.

47. Florez, J.; Muniz, J.; Portugal, L. Pedestrian Quality of Service: Lessons from Maracanã Stadium. Procedia Soc. Behav. Sci. 2014, 160, 130-139. [CrossRef]

48. Nakamura, K. Experimental analysis of walkability evaluation using virtual reality application. Environ. Plan. B Urban Anal. City Sci. 2020, 239980832098074. [CrossRef]

49. Hair, J.F.; Black, W.C.; Babin, B.J.; Anderson, R.E. Multivariate Data Analysis; Cengage: Hampshire, UK, 2019. 